\title{
CHOSEN: A synthesis of hydrometeorological data from 30 intensively monitored watersheds across the US
}

\author{
Liang Zhang ${ }^{1}$, Edom Moges ${ }^{1}$, Elizabeth Coda ${ }^{1}$, Tianchi Liu ${ }^{1}$, adam wymore ${ }^{2}$, Zexuan Xu ${ }^{3}$, \\ James Kirchner ${ }^{4}$, and Laurel Larsen ${ }^{1}$ \\ ${ }^{1}$ University of California Berkeley \\ ${ }^{2}$ University of New Hampshire \\ ${ }^{3}$ Lawrence Berkeley National Laboratory \\ ${ }^{4}$ ETH Zurich
}

October 1, 2020

\begin{abstract}
Hydrological analyses and their associated uncertainties are a function of their supporting observational datasets. Publicly available large-sample hydrology datasets covering a range of climates, times, and locations can be used to support inter-watershed comparisons, pattern identification, and watershed regionalization studies. However, most of the large-sample datasets are limited to a series of basic measurements such as precipitation, air temperature, and streamflow. Here we synthesized data from 30 intensively monitored catchments with soil moisture, snowmelt, and other hydrometeorological observations at daily scale across the US. This data synthesis product, CHOSEN (CONUS/Comprehensive Hydrologic Observatory SEnsor Network), includes watersheds from the Long-Term Ecological Research (LTER) and Critical Zone Observatory (CZO) networks, and several other ecological and hydrological observatories. Catchments span diverse climate gradients and encompass multiple biomes and ecosystems. To achieve a consistent and standardized data product, we first implemented data cleaning and control procedures with strict variable naming conventions and unit conversions. Following data quality control, data processing methods, including gap filling by interpolation, linear regression, and climate catalog-based techniques, were implemented to produce alternative level-2 products. The data and metadata were written into self-describing NetCDF files, facilitating ease of access by multiple computer platforms. All python coding scripts, ranging from processing to accessing the NetCDF files, are publicly available, along with a user-friendly tutorial. The standardizations adopted here, and the availability of the data-processing pipeline, will facilitate future additions of new observations to this database. We anticipate that this synthesis will support comparative long-term hydrological studies and contribute to a growing body of open-source research in watershed and ecosystem science.
\end{abstract}

\section{Acknowledgments}

This work is supported by the US Geological Survey Powell Center for Analysis and Synthesis, a Gordon and Betty Moore Foundation Data-Driven Discovery Investigator grant to LL, and the Jupyter Meets the Earth project, funded by NSF grant number (UC Berkeley: 1928406, NCAR: 1928374). Partial support for ASW was provided by the National Science Foundation and the Experimental Program to Stimulate Competitive Research (EPSCoR: EPS-1929148; Canary in the Watershed). We thank all the scientists and technicians from the US. Long-Term Ecological Research Network and Critical Zone Observatory program whose work has generated most of the data compiled here. We thank Lawrence Berkeley National Laboratory, Dry Creek Experimental Watershed (DCEW), Dr. Adrian Harpold who have provided us with data from the East River, Sagehen, and Dry Creek watersheds, and the Powell Center Working Group on Watershed 
Storage and Controls whose suggestions helped frame this project. We also thank Dr. Lindsey Heagy and Dr. Fernando Pérez for providing us with great suggestions for data publication and future development.

\section{Introduction}

Hydrometeorological data are essential for decision making in water resources engineering and management, and for developing predictive models for how watersheds and ecosystems respond to perturbation. Extreme-event analysis, flood mapping, and hydrological model building, calibration, and validation all rely on hydrometeorological data (Borga et al., 2011; Clark et al., 2008; Khan et al., 2011; Marchi et al., 2010; Razavi \& Coulibaly, 2013). Although different models require various data inputs, most models could benefit from intensively measured hydrometeorological data spanning diverse catchments. Notably, the continued development of both data-driven models and physically based distributed models requires comprehensive data for their execution and validation (Andersen et al., 2001; Asong et al., 2020; Kumar et al., 2008; Nord et al., 2017). Cross-site synthesis can also provide core knowledge to scale up hillslope to global processes and thus improve Earth system models (Fan et al., 2019).

Besides benefiting the development of hydrological and ecosystem models, comprehensive catchment data sets could also improve site-specific and comparative cross-site studies. Place-based studies, such as flood prediction (Rozalis et al., 2010), dominant hydrological process analysis (Schmocker-Fackel et al., 2007; Western et al., 2004), and climate change impact investigations (Jha et al., 2004) are critical in local decision making and hypothesis testing. For example, Tennant et al. (2020) made use of multiple hydrometeorological variables to improve the understanding of the dominant controls on catchment discharge. Conversely, comparative hydrology aims to understand hydrological variability and the role of catchment characteristics, and to develop generally applicable models (Kuentz et al., 2017; Sawicz et al., 2011; Wymore et al., 2017). For example, Wymore et al. (2017) studied concentration-discharge relationships across 10 tropical watersheds with different landscape characteristics. With the increasing interest in comparative hydrology, demand for large-sample hydrological datasets has grown (Gupta et al., 2014). Such large-sample hydrology datasets support continental-scale hydrological studies, facilitate comparative hydrological analysis, and help to identify hydrological patterns (Addor et al., 2017; Duan et al., 2006). The comprehensive dataset presented in this study, a synthesis of streamflow and hydrometeorology data across intensively monitored catchments, will serve the hydrological research community by providing quality-controlled, ready-to-use data with a coordinated and standardized structure.

CHOSEN (Comprehensive Hydrologic Observatory SEnsor Network) is a compilation of data from the LongTerm Ecological Research (LTER) and Critical Zone Observatory (CZO) networks, and several other ecological and hydrological observatories. Initiatives like the LTER and CZO networks seek to create opportunities for analyses that span multiple watersheds and ecosystem types. However, cross-network and cross-site comparative efforts are often hampered by site-to-site differences in which variables are measured, how they are processed and formatted, and how they are reported. The work of finding diverse catchment data sets, extracting them from whatever formats they are stored in, and cleaning and harmonizing them requires a significant investment of time and effort. CHOSEN aims to address these challenges by providing a ready-touse comprehensive hydrometeorological dataset, with an accompanying open-access data processing pipeline allowing for the incorporation of new data and the continued evolution of the data set.

Several previous data synthesis efforts, including the MOPEX (Duan et al., 2006) and CAMELS datasets (Addor et al., 2017), have also sought to facilitate large-sample hydrological studies. Compared with those previous datasets, the CHOSEN dataset focuses strictly on intensively monitored sites with field measurements that extend beyond just discharge, precipitation, and weather, to include snow depth and snow water equivalent (SWE), soil moisture, soil temperature, and isotope data. Time series of these variables are critical to process-based hydrological and ecological studies, for example, process-oriented benchmarking evaluation (Nearing et al., 2018), and coupling physical process models with machine learning (Reichstein et al., 2019). Such datasets can also assist in understanding the physically based mechanisms underlying 
watershed behavior (Werkhoven et al., 2008) and ecosystem resilience (Qi et al., 2016). In some catchments, soil moisture patterns have been used to reveal the dynamics of water storage and transport in the landscape (Bracken et al., 2013; James \& Roulet, 2007; Tetzlaff et al., 2011). Snow data are essential in investigating hydrological processes and simulating runoff in snow-dominated areas (Rasmussen et al., 2011; Foy et al., 2015). Isotope time series facilitate the tracing of water fluxes through watersheds (Hrachowitz et al., 2013). Rather than merely treating basins as black boxes that convert precipitation inputs to streamflow outputs, the age distribution of the water derived from isotope data provides information about storage timescales within catchments (Kirchner et al., 2000; McDonnell et al., 2010; Soulsby et al., 2006; Tetzlaff et al., 2014). By focusing on intensively monitored catchments with more comprehensive data than just discharge, precipitation, and weather, the CHOSEN dataset seeks to facilitate the understanding of hydrological processes, development of simulation models, and effective management of catchments and ecosystems spanning diverse environmental conditions.

\section{Site overview, workflow and methodology}

\subsection{Site overview}

We synthesized data from 30 intensively monitored watersheds across the US (Figure 1). Sixteen of the 30 watersheds are part of the LTER network, 11 from the CZO network, and the remaining three are East River, CO, Dry Creek, ID, and Sagehen Creek, CA. Data from these sites were provided by collaborators and have not been previously publicly available in a consistent format. Additional metadata describing these watersheds, including the data web links, drainage area, location and basic weather information, are provided in the supplementary material.

Figure 1. Geographical distribution of the watersheds

\subsection{Workflow overview}

The synthesis process followed the workflow of data downloading, data quality control and cleaning, data aggregation, gap-filling in daily time series, and finally, writing to NetCDF format. To extract the desired data, we carefully inspected the source websites for information about how the original data were measured, processed, and recorded. Our data cleaning and quality control procedures included scanning for unrealistic values and cross-checking data flag reports. After unrealistic values were removed, any time series that were recorded at sub-daily intervals were aggregated to daily time steps. Subsequently, three levels of gap-filling methods (interpolation, regression, and climate catalog; see Section 2.4) were applied to the daily-scaled data. The resulting data were stored in NetCDF format using a consistent structure and layout, together with metadata which provided additional information including variable units, station names, locations and record lengths.

\subsection{Data downloading and cleaning}

For each site, we acquired (if available) time series data of streamflow, precipitation, air temperature, solar radiation, relative humidity, wind direction, wind speed, SWE, snow depth, vapor pressure, soil moisture, soil temperature, and isotope values. For the convenience of cross-watershed research and intercomparison of datasets, variable naming standards and their units were made consistent, following Addor et al.'s (2020) suggested format for large sample hydrology datasets. As detailed in the data pipeline Jupyter Notebooks attached to the CHOSEN database, we aggregated any hourly time series in one of two different ways: cumulative variables were summed, and rate variables were averaged. 


\subsection{Gap-filling methods}

Gaps in the cleaned and aggregated daily data were filled using one of three techniques, depending on the length of the gap and availability of complementary data. The first technique involved linear interpolation between the two nearest non-missing values. Linear interpolation was applied to gaps of less than seven days, over which seasonal effects can be considered trivial. Longer gaps were filled by regression for those catchments with multiple monitoring stations (Pappas et al., 2014). To implement spatial regression, we first evaluated the correlation coefficients between the station with missing values and all the other stations within the watershed. We then used the data from the station with the highest correlation coefficient to estimate the regression parameters. If the highest correlation coefficient was less than 0.7 , or if no data were available from other stations contemporarily, the missing values were reconstructed using the climate catalog technique. The climate catalogue method filled gaps by using data from the same site for a different year (the one containing at least 9 months of data and with the highest correlation coefficient greater than 0.7 to the year in which values were missing). For example, suppose a catchment's only streamflow gauge was missing all of April's measurements in 2002. In this case, we would first group the available data by year, and calculate the correlation coefficients between daily streamflows in 2002 and the other years. If the 2002 data correlated most strongly with data from 2006, then 2006's April 1st data point replaced the missing value from April 1st 2002, with the addition of a Gaussian random number scaled by the standard deviation of all April 1st values from all the years of record.

Figure 2. Data pipeline and visualizations of cleaning methods: a) interpolation, b) regression and c) climate catalog

To assure the quality of reconstructed data (interpolated, regressed, or based on climate catalog), we deleted any reconstructed values that fell outside of the thresholds that were originally used to detect unrealistic data. After all the data filling methods were applied, a flag table was generated indicating the technique that was used to create each filled data point. All the python coding scripts for processing methods are available on GitLab (https://gitlab.com/esdl/chosen) and will be published on Zenodo (DOI: 10.5281/zenodo.4060384) open to the public along with a Jupyter Notebook tutorial.

\subsection{NetCDF data product}

We stored and published the processed data in NetCDF format. NetCDF is emerging as the data standard for large-sample hydrology, as well as for other large-sample products across the geosciences, particularly climate science and remote sensing (Liu et al., 2016; Romañach et al., 2015; Signell et al., 2008). The NetCDF library is designed to read and write multi-dimensional scientific data in a well-structured manner. The library enables writing data in several coordinate dimensions, accommodating multiple measurement stations. The machine-based interface makes data highly accessible and easily portable across various computer platforms. Data (variables) and metadata (corresponding attributes) are intrinsically linked and stored in the same file, making the data set self-documenting.

We generated one NetCDF file for each watershed to store its data and metadata. In these NetCDF files, there are four kinds of variables. Hydrometeorological variables are stored in two-dimensional arrays (i.e., by time and location), along with flag variables having the same number and array dimensions. The timestamp variable is a one-dimensional array of measurement dates and times. Lastly, a grid variable contains information about gauges and monitoring stations, including their names, latitudes, and longitudes. The attributes include website links, units, full names, and record starting and ending dates (Figure 3).

Figure 3. Variables, corresponding dimensions and attributes in NetCDF files 


\section{Data description}

\subsection{Data overview}

The CHOSEN database contains up to 13 different hydrometeorological variables, including streamflow, precipitation, air temperature, solar radiation, relative humidity, wind direction, wind speed, SWE, snow depth, vapor pressure, soil moisture, soil temperature, and isotope values, with availability varying from site to site (Figure 4). The HJ Andrews and Bonanza LTERs have measurements of all 13 variables, with most of the other watersheds having data of around ten hydrometeorological variables. Discharge record lengths range from three years at Calhoun to 78 years at the San Diego River (California Current Ecosystem LTER), with a median of 19 years.

Figure 4. Span of time series availability and duration across watersheds

Among all the 13 hydrometeorology variables included in the dataset, discharge, precipitation, snow depth, soil moisture, and isotope data are particularly important for hydrologic process studies. Discharge and precipitation time series are available in all CHOSEN watersheds (Figure 5), and seven catchments have soil moisture and snow measurements with records exceeding five years. Although publicly available isotope data are limited, we identified six watersheds with isotope time series longer than one year (Figure 4).

Figure 5. Distributions of record spans for different variables

\subsubsection{Precipitation}

In the CHOSEN dataset, 27 watersheds have more than five years of precipitation data, and 20 watersheds have more than ten years (Figure 5). Twenty-five watersheds have less than $10 \%$ missing precipitation values, increasing to 29 watersheds after applying gap-filling methods (Figure S1). The sparsest precipitation raw data are from the Bonanza site, where $24 \%$ of the missing values were filled by regression. More precipitation gap-filling information is available in the supplementary material.

\subsubsection{Soil moisture}

Soil moisture is essential for investigating hydrologic connectivity and runoff processes, especially where vertical flow dominates (Bracken et al., 2013). Soil moisture measurements are available in 18 watersheds (Figure 5), usually including multiple stations and depths. Seventeen of these catchments have less than $10 \%$ missing soil moisture data after gap-filling (Figure S2). The longest soil moisture records on average are in the HJ Andrews watershed, including multiple stations dispersed in several sub-watersheds monitoring at different depths. Like the HJ Andrews watershed, other sites commonly measure soil moisture data at multiple stations, facilitating gap-filling through spatial regression.

\subsubsection{Snow depth / SWE}

At high latitudes and altitudes, snowmelt can play an important role in streamflow generation and nutrient export, and snow accumulation and melt may be particularly sensitive to climate change. Eight of the CHOSEN watersheds have snow depth data with less than $10 \%$ missing values after gap-filling (Figure S3). Sagehen watershed has the longest snow depth record (61 years), with 39 years of SWE data (Table S2).

\subsubsection{Isotope data}

Isotope tracers (e.g., ${ }^{18} \mathrm{O}$ and deuterium) are important for estimating catchment transit time distributions, which, along with hydrologic response timescales, can be used to characterize the temporal dynamics of the water cycle. Though publicly available isotope measurements are less abundant than hydrometeorological data, six of the CHOSEN watersheds have publically available isotope time series. Among those watersheds, Shale Hills has the longest isotope time series, consisting of 1103 days of isotope measurements between 
2008-03-28 and 2011-12-31. Most of the sites have sub-weekly $\delta^{18} \mathrm{O}$ and $\delta^{2} \mathrm{H}$ measurements in precipitation and streamflow (Table S4).

\subsection{Example data from Dry Creek watershed}

This section presents example data from the Dry Creek Experimental Watershed (DCEW), located in the semi-arid southwestern region of Idaho, USA, $16 \mathrm{~km}$ northeast of the city of Boise. Raw data were downloaded from the Boise State University research pagehttps://www.boisestate.edu/drycreek/dry-creek-data/ . Daily measurements of discharge, precipitation, soil moisture, snow depth, and six other hydrometeorological variables were collected starting in 1999 at multiple streamflow gauges, weather stations, and soil moisture sensors distributed in this area (Figure 6).

Figure 6. Dry creek experimental watershed

(Source:https://www.boisestate.edu/drycreek/dry-creek-data/)

Over half of the variables at Dry Creek have less than $10 \%$ missing values at daily time steps. After applying gap-filling methods, all hydrometeorological variables except snow depth have less than $10 \%$ missing values (Figure 7). The sparsity of snow depth data is due to the ephemeral nature of the region's snowpack.

Figure 7. Data filling methods applied to Dry Creek data

The intensively monitored data included in CHOSEN allow for detailed analyses of hydrometeorology variables at both the seasonal and interannual time-scale. Here, we briefly describe some of the gap-filled data from the 2011-2012 hydrological year at Dry Creek (Figure 8). For streamflow, the highest discharge values were monitored at Lower Gauge (LG) which is located downstream of the watershed. The lowest discharge values are from two tributaries: Treeline (TL) and Bogus South Gauge (BSG). Patterns of precipitation match the responses in streamflow, especially in January and April. Springtime snowmelt is reflected in both a decrease in snow depth and persistent high flows during March and April. The soil moisture time series vary greatly from station to station, but generally reflect seasonal patterns of precipitation, snowmelt, and evaporative demand, with shorter-term fluctuations in shallower sensors showing the influence of individual precipitation events. This example highlights how CHOSEN data can be instrumental in understanding the responses of soil moisture and discharge to hydrometeorological drivers.

Figure 8. Cleaned Dry Creek daily data from 2011-10-01 to 2012-09-30

\section{Summary and outlook}

Hydrometeorological data are critical in model development and water resources management. In this work, we compiled hydrometeorological data from 30 intensively monitored watersheds. In addition to standard measurements of precipitation, air temperature and streamflow, the CHOSEN dataset also includes soil moisture, SWE, snow depth, isotopes, and other hydrometeorology variables. Most of the raw data were downloaded from publicly available resources, including the LTER and US CZO networks.

Since raw data often have errors, gaps, and inconsistent formats across sites, we applied quality control procedures, gap-filled missing data, and standardized the data format. The three-step gap-filling approach consisted of interpolation, regression, and climate catalog methods. We also generated flag tables denoting the different data types (raw, missing, or filled) and gap-filling methods. Data users can update or change the gap-filling techniques with the help of these flag tables. Finally, we published the synthesis product in NetCDF format along with Jupyter Notebook examples demonstrating the cleaning procedures and how to access the data.

Different large sample hydrological datasets are best adapted to various research pursuits and questions (Addor et al., 2020). Compared with other large sample hydrological datasets, our dataset seeks to facilitate 
hydrological and ecological studies that require a broad set of hydrometeorological variables and time series data. For instance, hydrological model development may benefit from having soil moisture, snowmelt and streamflow data as part of its multi-objective calibration function (Andersen et al., 2001), while isotope data can support studies that focus on watershed storage estimates and transport (Perrin et al., 2003; Sprenger et al., 2018). Similarly, the CHOSEN dataset can promote data-driven models focused on predictions beyond streamflow, which will allow them to be more comprehensive than mere discharge predictors. And for the ecological community, these data could be used to better understand how processes such as microbial biogeochemical reactions and evapotranspiration respond to changing hydrological regimes and climate variability. Besides this data release, future data products can include catchment physical attributes such as watershed topography and soil characteristics. The availability of such physical watershed attributes can further assist in comparative studies using both data-driven and distributed models, possibly leading to prediction in ungauged basins and transferability of model parameters among catchments (Razavi \& Coulibaly, 2013; Sivapalan et al., 2003; Zelelew \& Alfredsen, 2014).

While other large-sample hydrological datasets often contain more watersheds than CHOSEN does currently, to the best of our knowledge, CHOSEN reflects one of the largest open-source collections of hydrometeorological data from intensely and comprehensively monitored watersheds. Similar to the CAMELS initiative (Addor et al., 2017), which has now encouraged the release of data from different groups and countries (CAMELS-UK(Coxon et al., 2020), CAMELS-Chile (Alvarez-Garreton et al., 2018)), we hope that this data product will encourage different groups to publicly release comprehensive data sets to enrich hydrological analysis.

\section{Reference}

Addor, N., Newman, A. J., Mizukami, N., \& Clark, M. P. (2017). The CAMELS data set: catchment attributes and meteorology for large-sample studies. Hydrol. Earth Syst. Sci. , 21.

Addor, N., Do, H. X., Alvarez-Garreton, C., Coxon, G., Fowler, K., \& Mendoza, P. A. (2020). Large-sample hydrology: recent progress, guidelines for new datasets and grand challenges. Hydrological Sciences Journal , 65 (5), 712-725. https://doi.org/10.1080/02626667.2019.1683182

Alvarez-Garreton, C., Mendoza, P. A., Boisier, J. P., Addor, N., Galleguillos, M., Zambrano-Bigiarini, M., et al. (2018). The CAMELS-CL dataset: catchment attributes and meteorology for large sample studies Chile dataset. Hydrology and Earth System Sciences ,22 (11), 5817-5846. https://doi.org/10.5194/hess-22$5817-2018$

Andersen, J., Refsgaard, J. C., \& Jensen, K. H. (2001). Distributed hydrological modelling of the Senegal River Basin — model construction and validation. Journal of Hydrology , 247 (3), 200-214. https://doi.org/10.1016/S0022-1694(01)00384-5

Asong, Z. E., Elshamy, M. E., Princz, D., Wheater, H. S., Pomeroy, J. W., Pietroniro, A., \& Cannon, A. (2020). High-resolution meteorological forcing data for hydrological modelling and climate change impact analysis in the Mackenzie River Basin. Earth System Science Data ,12 (1), 629-645. https://doi.org/10.5194/essd-12-629-2020

Borga, M., Anagnostou, E. N., Blöschl, G., \& Creutin, J.-D. (2011). Flash flood forecasting, warning and risk management: the HYDRATE project. Environmental Science 85 Policy , 14 (7), 834-844. https://doi.org/10.1016/j.envsci.2011.05.017

Bracken, L. J., Wainwright, J., Ali, G. A., Tetzlaff, D., Smith, M. W., Reaney, S. M., \& Roy, A. G. (2013). Concepts of hydrological connectivity: Research approaches, pathways and future agendas.Earth-Science Reviews , 119 , 17-34. https://doi.org/10.1016/j.earscirev.2013.02.001 
Clark, M. P., Rupp, D. E., Woods, R. A., Zheng, X., Ibbitt, R. P., Slater, A. G., et al. (2008). Hydrological data assimilation with the ensemble Kalman filter: Use of streamflow observations to update states in a distributed hydrological model. Advances in Water Resources ,31 (10), 1309-1324. https://doi.org/10.1016/j.advwatres.2008.06.005

Coxon, G., Addor, N., Bloomfield, J. P., Freer, J., Fry, M., Hannaford, J., et al. (2020). CAMELS-GB: Hydrometeorological time series and landscape attributes for 671 catchments in Great Britain. Earth System Science Data Discussions , 1-34. https://doi.org/10.5194/essd-2020-49

Duan, Q., Schaake, J., Andréassian, V., Franks, S., Goteti, G., Gupta, H. V., et al. (2006). Model Parameter Estimation Experiment (MOPEX): An overview of science strategy and major results from the second and third workshops. Journal of Hydrology , 320 (1), 3-17. https://doi.org/10.1016/j.jhydrol.2005.07.031

Fan, Y., Clark, M., Lawrence, D. M., Swenson, S., Band, L. E., Brantley, S. L., et al. (2019). Hillslope Hydrology in Global Change Research and Earth System Modeling. Water Resources Research , 55 (2), 1737-1772. https://doi.org/10.1029/2018WR023903

Foy, C., Arabi, M., Yen, H., Gironás, J., \& Bailey, R. T. (2015). Multisite Assessment of Hydrologic Processes in Snow-Dominated Mountainous River Basins in Colorado Using a Watershed Model.Journal of Hydrologic Engineering , 20 (10), 04015017. https://doi.org/10.1061/(ASCE)HE.1943-5584.0001130

Gupta, H. V., Perrin, C., Blöschl, G., Montanari, A., Kumar, R., Clark, M., \& Andréassian, V. (2014). Large-sample hydrology: a need to balance depth with breadth. Hydrology and Earth System Sciences ,18 (2), 463-477. https://doi.org/10.5194/hess-18-463-2014

Hrachowitz, M., Savenije, H., Bogaard, T. A., Tetzlaff, D., \& Soulsby, C. (2013). What can flux tracking teach us about water age distribution patterns and their temporal dynamics? Hydrology and Earth System Sciences , 17 (2), 533-564. https://doi.org/10.5194/hess-17-533-2013

James, A. L., \& Roulet, N. T. (2007). Investigating hydrologic connectivity and its association with threshold change in runoff response in a temperate forested watershed. Hydrological Processes , 21 (25), 3391-3408. https://doi.org/10.1002/hyp.6554

Jha, M., Pan, Z., Takle, E. S., \& Gu, R. (2004). Impacts of climate change on streamflow in the Upper Mississippi River Basin: A regional climate model perspective. Journal of Geophysical Research: Atmospheres , 109 (D9). https://doi.org/10.1029/2003JD003686

Khan, S. I., Hong, Y., Wang, J., Yilmaz, K. K., Gourley, J. J., Adler, R. F., et al. (2011). Satellite Remote Sensing and Hydrologic Modeling for Flood Inundation Mapping in Lake Victoria Basin: Implications for Hydrologic Prediction in Ungauged Basins. IEEE Transactions on Geoscience and Remote Sensing , 49 (1), 85-95. https://doi.org/10.1109/TGRS.2010.2057513

Kirchner, J. W., Feng, X., \& Neal, C. (2000). Fractal stream chemistry and its implications for contaminant transport in catchments. Nature , 403 (6769), 524-527. https://doi.org/10.1038/35000537

Kuentz, A., Arheimer, B., Hundecha, Y., \& Wagener, T. (2017). Understanding hydrologic variability across Europe through catchment classification. Hydrology and Earth System Sciences ,21 (6), 2863-2879. https://doi.org/10.5194/hess-21-2863-2017

Kumar, S. V., Peters-Lidard, C. D., Eastman, J. L., \& Tao, W.-K. (2008). An integrated high-resolution hydrometeorological modeling testbed using LIS and WRF. Environmental Modelling \& Software ,23 (2), 169-181. https://doi.org/10.1016/j.envsoft.2007.05.012

Liu, H., van Oosterom, P., Hu, C., \& Wang, W. (2016). Managing Large Multidimensional Array Hydrologic Datasets: A Case Study Comparing NetCDF and SciDB. Procedia Engineering , 154, 207-214. https://doi.org/10.1016/j.proeng.2016.07.449 
Marchi, L., Borga, M., Preciso, E., \& Gaume, E. (2010). Characterisation of selected extreme flash floods in Europe and implications for flood risk management. Journal of Hydrology ,394 (1), 118-133. https://doi.org/10.1016/j.jhydrol.2010.07.017

McDonnell, J. J., McGuire, K., Aggarwal, P., Beven, K. J., Biondi, D., Destouni, G., et al. (2010). How old is streamwater? Open questions in catchment transit time conceptualization, modelling and analysis.Hydrological Processes , 24 (12), 1745-1754. https://doi.org/10.1002/hyp.7796

Nearing, G. S., Ruddell, B. L., Clark, M. P., Nijssen, B., \& Peters-Lidard, C. (2018). Benchmarking and Process Diagnostics of Land Models. Journal of Hydrometeorology , 19 (11), 1835-1852. https://doi.org/10.1175/JHM-D-17-0209.1

Nord, G., Boudevillain, B., Berne, A., Branger, F., Braud, I., Dramais, G., et al. (2017). A high space-time resolution dataset linking meteorological forcing and hydro-sedimentary response in a mesoscale Mediterranean catchment (Auzon) of the Ardeche region, France. https://doi.org/10.5194/essd-9-221-2017

Pappas, C., Papalexiou, S. M., \& Koutsoyiannis, D. (2014). A quick gap filling of missing hydrometeorological data. Journal of Geophysical Research: Atmospheres , 119 (15), 9290-9300. https://doi.org/10.1002/2014JD021633

Perrin, J., Jeannin, P.-Y., \& Zwahlen, F. (2003). Epikarst storage in a karst aquifer: a conceptual model based on isotopic data, Milandre test site, Switzerland. Journal of Hydrology , 279 (1), 106-124. https://doi.org/10.1016/S0022-1694(03)00171-9

Qi, M., Feng, M., Sun, T., \& Yang, W. (2016). Resilience changes in watershed systems: A new perspective to quantify long-term hydrological shifts under perturbations. Journal of Hydrology , 539 , 281-289. https://doi.org/10.1016/j.jhydrol.2016.05.039

Razavi, T., \& Coulibaly, P. (2013). Streamflow Prediction in Ungauged Basins: Review of Regionalization Methods. Journal of Hydrologic Engineering , 18 (8), 958-975. https://doi.org/10.1061/(ASCE)HE.19435584.0000690

Reichstein, M., Camps-Valls, G., Stevens, B., Jung, M., Denzler, J., Carvalhais, N., \& Prabhat. (2019). Deep learning and process understanding for data-driven Earth system science. Nature ,566 (7743), 195-204. https://doi.org/10.1038/s41586-019-0912-1

Romañach, S. S., McKelvy, M., Suir, K., \& Conzelmann, C. (2015). EverVIEW: A visualization platform for hydrologic and Earth science gridded data. Computers $\&$ Geosciences , 76 , 88-95. https://doi.org/10.1016/j.cageo.2014.12.004

Rozalis, S., Morin, E., Yair, Y., \& Price, C. (2010). Flash flood prediction using an uncalibrated hydrological model and radar rainfall data in a Mediterranean watershed under changing hydrological conditions. Journal of Hydrology , 394 (1), 245-255. https://doi.org/10.1016/j.jhydrol.2010.03.021

Sawicz, K., Wagener, T., Sivapalan, M., Troch, P. A., \& Carrillo, G. (2011). Catchment classification: empirical analysis of hydrologic similarity based on catchment function in the eastern USA.Hydrology and Earth System Sciences Discussions , 8 (3), 4495-4534. https://doi.org/10.5194/hessd-8-4495-2011

Schmocker-Fackel, P., Naef, F., \& Scherrer, S. (2007). Identifying runoff processes on the plot and catchment scale. Hydrology and Earth System Sciences Discussions , 11 (2), 891-906.

Signell, R. P., Carniel, S., Chiggiato, J., Janekovic, I., Pullen, J., \& Sherwood, C. R. (2008). Collaboration tools and techniques for large model datasets. Journal of Marine Systems , 69 (1), 154-161. https://doi.org/10.1016/j.jmarsys.2007.02.013

Sivapalan, M., Takeuchi, K., Franks, S. W., Gupta, V. K., Karambiri, H., Lakshmi, V., et al. (2003). IAHS Decade on Predictions in Ungauged Basins (PUB), 2003-2012: Shaping an exciting future for the hydrological sciences. Hydrological Sciences Journal , 48 (6), 857-880. https://doi.org/10.1623/hysj.48.6.857.51421 
Soulsby, C., Tetzlaff, D., Rodgers, P., Dunn, S., \& Waldron, S. (2006). Runoff processes, stream water residence times and controlling landscape characteristics in a mesoscale catchment: An initial evaluation. Journal of Hydrology , 325 (1), 197-221. https://doi.org/10.1016/j.jhydrol.2005.10.024

Sprenger, M., Tetzlaff, D., Buttle, J., Carey, S. K., McNamara, J. P., Laudon, H., et al. (2018). Storage, mixing, and fluxes of water in the critical zone across northern environments inferred by stable isotopes of soil water. Hydrological Processes , 32 (12), 1720-1737. https://doi.org/10.1002/hyp.13135

Tetzlaff, D., Birkel, C., Dick, J., Geris, J., \& Soulsby, C. (2014). Storage dynamics in hydropedological units control hillslope connectivity, runoff generation, and the evolution of catchment transit time distributions. Water Resources Research , 50 (2), 969-985. https://doi.org/10.1002/2013WR014147

Tetzlaff, Doerthe, McNamara, J. P., \& Carey, S. K. (2011). Measurements and modelling of storage dynamics across scales. Hydrological Processes , 25 (25), 3831-3835. https://doi.org/10.1002/hyp.8396

Werkhoven, K. van, Wagener, T., Reed, P., \& Tang, Y. (2008). Characterization of watershed model behavior across a hydroclimatic gradient. Water Resources Research , 44 (1). https://doi.org/10.1029/2007WR006271

Western, A. W., Zhou, S.-L., Grayson, R. B., McMahon, T. A., Blöschl, G., \& Wilson, D. J. (2004). Spatial correlation of soil moisture in small catchments and its relationship to dominant spatial hydrological processes. Journal of Hydrology , 286 (1), 113-134. https://doi.org/10.1016/j.jhydrol.2003.09.014

Wymore, A. S., Brereton, R. L., Ibarra, D. E., Maher, K., \& McDowell, W. H. (2017). Critical zone structure controls concentration-discharge relationships and solute generation in forested tropical montane watersheds. Water Resources Research , 53 (7), 6279-6295. https://doi.org/10.1002/2016WR020016

Zelelew, M. B., \& Alfredsen, K. (2014). Transferability of hydrological model parameter spaces in the estimation of runoff in ungauged catchments. Hydrological Sciences Journal , 59 (8), 1470-1490. https://doi.org/10.1080/02626667.2013.838003

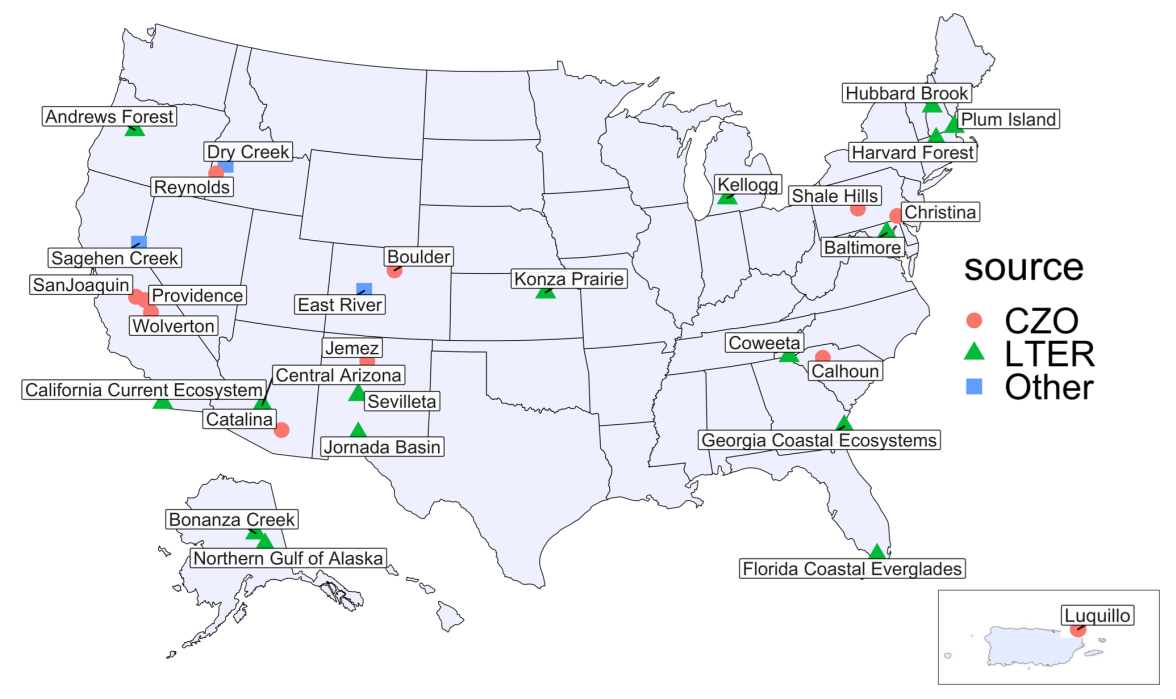




\section{Data Downloading \\ Quality Control and Cleaning \\ Data Aggregation}

Data Processing: Gap-filling Methods

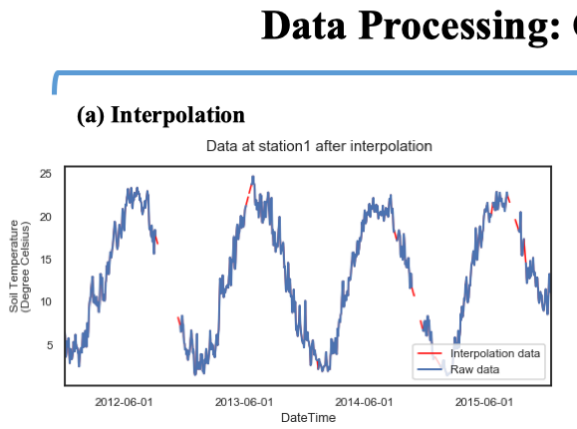

Lap-

(b) Regression
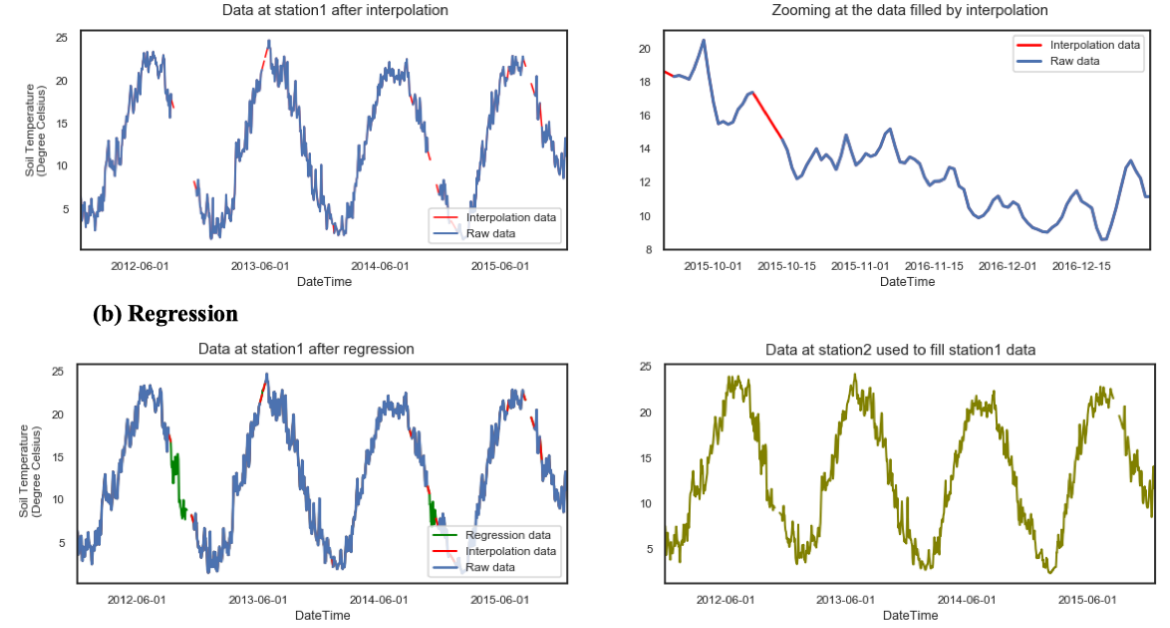

(c) Climate Catalog
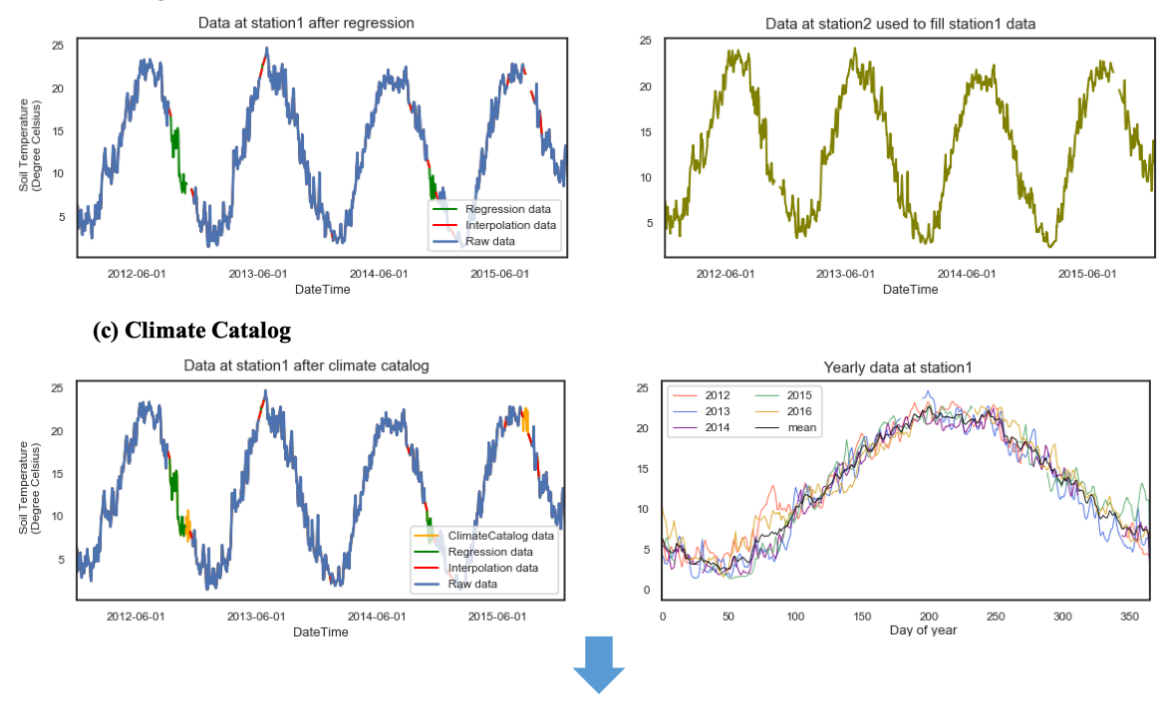

NetCDF File Generation 

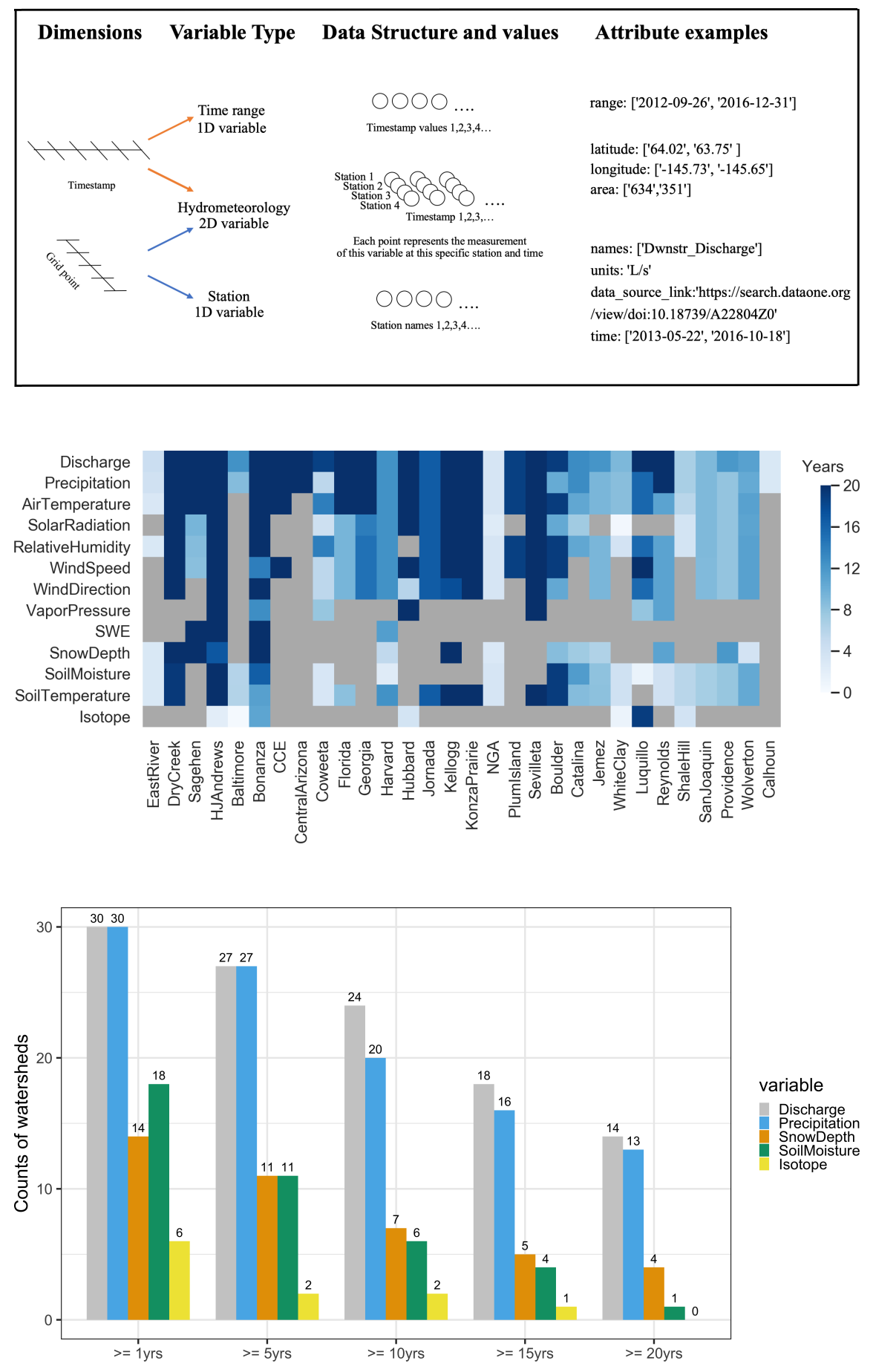

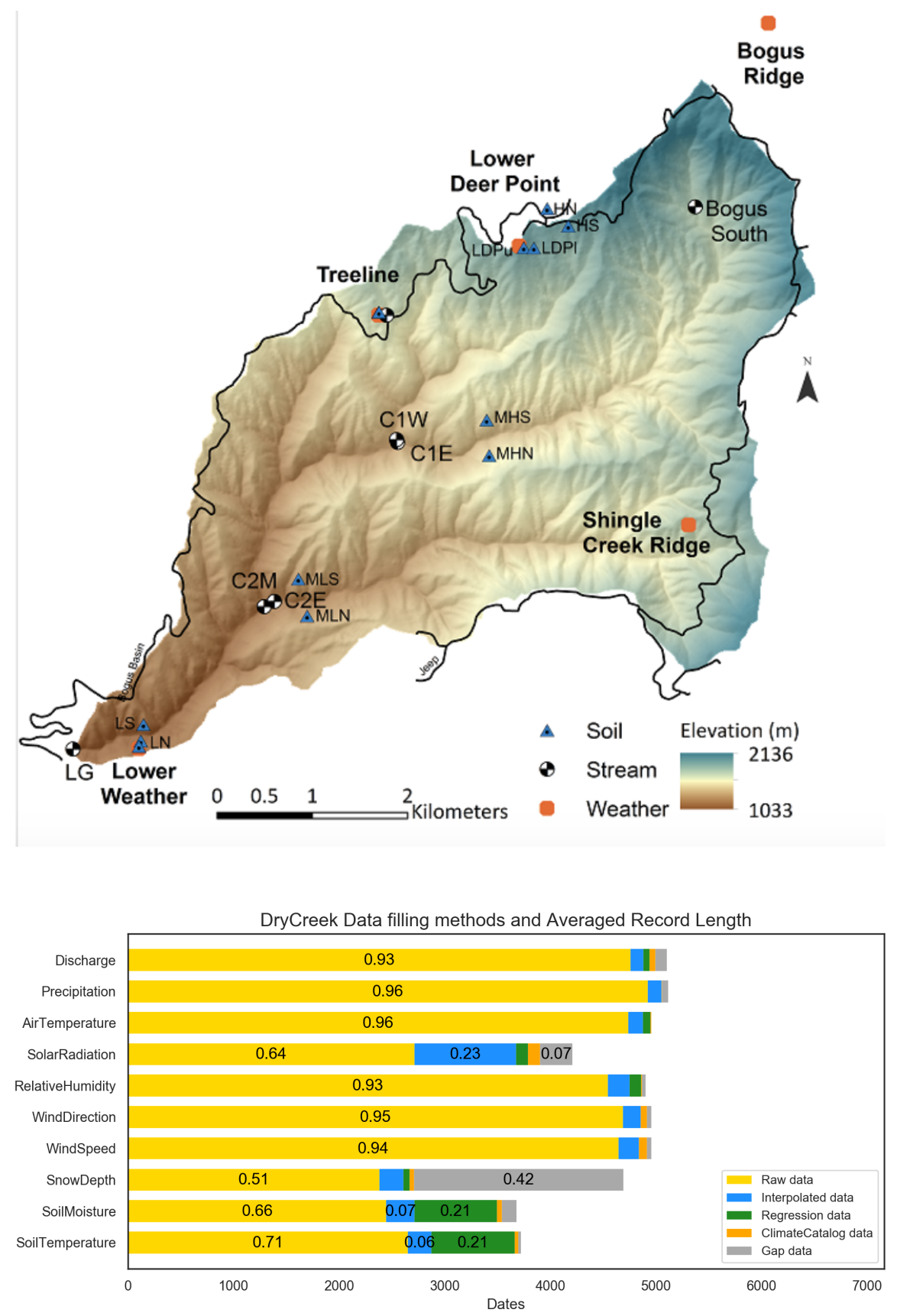
Discharge, Precipitation, Snow Depth, Soil Moisture time series in DryCreek Catchment from Treeline(TL), Bogus South Gauge(BSG) Lower Gauge(LG), Bogus Ridge Weather(BRW), Lower Deer Point(LDP), Shingle Creek Ridge(SCR), Lower Weather(LW) stations
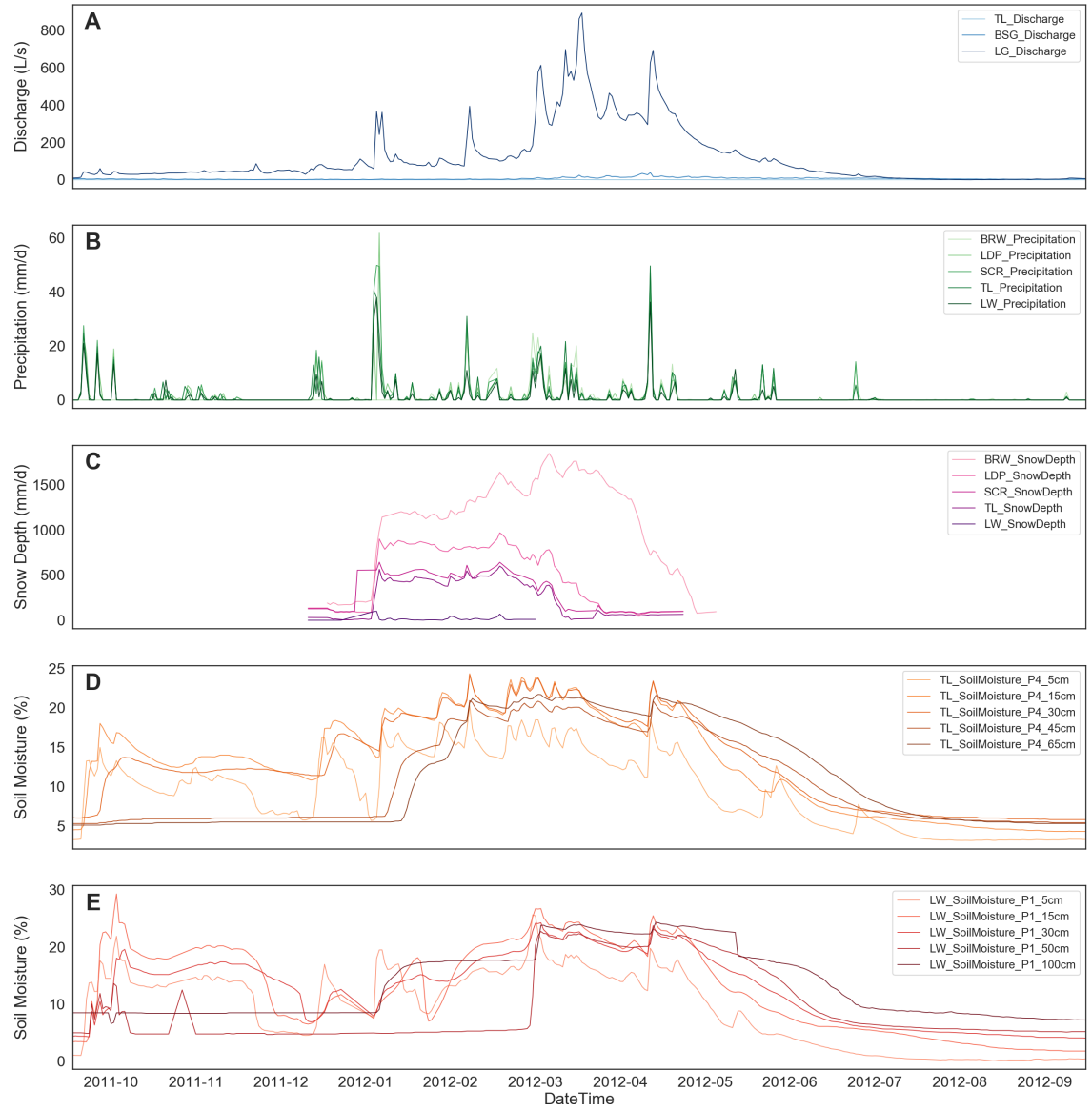